\title{
Changes in Distribution and Frequency of Fungi Associated With a Foliar Disease Complex of Pyrethrum in Australia
}

Frank S. Hay, Tasmanian Institute of Agriculture, School of Land and Food, University of Tasmania, Burnie, 7320, Australia; David H. Gent, United States Department of Agriculture - Agricultural Research Services (USDA-ARS), Forage Seed and Cereal Research Unit, and Oregon State University, Department of Botany and Plant Pathology, Corvallis, OR 97331; Stacey J. Pilkington, Tamieka L. Pearce, and Jason B. Scott, Tasmanian Institute of Agriculture, School of Land and Food, University of Tasmania, Burnie, 7320, Australia; and Sarah J. Pethybridge, Cornell University, School of Integrative Plant Science, Section of Plant Pathology and Plant-Microbe Biology, Geneva, NY 14456

\begin{abstract}
Hay, F. S., Gent, D. H., Pilkington, S. J., Pearce, T. L., Scott, J. B., and Pethybridge, S. J. 2015. Changes in distribution and frequency of fungi associated with a foliar disease complex of pyrethrum in Australia. Plant Dis. 99:1227-1235.

In Australia, pyrethrum (Tanacetum cinerariifolium) is affected by a foliar disease complex that can substantially reduce green leaf area and yield. Historically, the most important foliar disease of pyrethrum in Australia has been ray blight, caused by Stagonosporopsis tanaceti, and other fungi generally of minor importance. Temporal fluctuations in the frequency of fungi associated with foliar disease were quantified in each of 83 fields in northern Tasmania, Australia, during 2012 and 2013. Sampling was conducted throughout winter (April to July), spring (August to September), and summer (November) representing different phenological stages. Microsphaeropsis tanaceti, the cause of tan spot, was the pathogen most prevalent and isolated at the highest frequency, irrespective of sampling period. The next most common species was $S$. tanaceti, whose isolation frequency was low in winter and increased in spring and summer. Known pathogens of pyrethrum, Alternaria tenuissima, Colletotrichum tanaceti, and Stemphylium botryosum were recovered sporadically and at low frequency. Two species of potential importance, Paraphoma chrysanthemicola and Itersonilia perplexans, were also found at low frequency. This finding suggests a substantial shift in the dominant pathogen associated with foliar disease, from $S$. tanaceti to $M$. tanaceti, and coincides with an increase in defoliation severity in winter, and control

failures of the spring fungicide program. Factors associated with this finding were also investigated. Sensitivity of $M$. tanaceti and $S$. tanaceti populations to the fungicides boscalid and cyprodinil collected prior to and following disease control failures in the field were tested under in vitro conditions. A high proportion $(60 \%)$ of the M. tanaceti isolates obtained from fields in which no response to the spring fungicide program was found were insensitive to $50 \mu \mathrm{g}$ a.i./ml boscalid. This represented a 4.2-fold increase in the frequency of this phenotype within the $M$. tanaceti population over 2 years. No shifts in sensitivities to cyprodinil of $M$. tanaceti and $S$. tanaceti, or $S$. tanaceti to boscalid, were observed. Considering the increase in defoliation severity over winter, the benefits of applying fungicides in autumn, in addition to the commercial standard (spring only), were quantified in 14 individual field trials conducted in 2011 and 2012. Mixed-model analysis suggested fungicide application in autumn may improve pyrethrum growth during late winter and early spring, although effects on defoliation and yield were minimal. The increasing prevalence and isolation frequency of $M$. tanaceti and boscalid resistance within the population is of concern and highlights the urgent need for adoption of nonchemical methods for disease management in Australian pyrethrum fields.
\end{abstract}

Pyrethrum (Tanacetum cinerariifolium) is a perennial plant grown commercially for the insecticidal pyrethrins that are produced within secretory ducts on the achenes (Zito et al. 1983). Approximately 3,000 ha of pyrethrum is grown in Australia annually, accounting for approximately $70 \%$ of production worldwide. Pyrethrins are used in a variety of pest control products mainly in urban situations and are valued for having a rapid "knock-down" effect on a wide range of insects, low mammalian toxicity, and short half-life in the environment (Casida 1980).

Pyrethrum fields are established in spring by direct seeding. The first harvest occurs approximately 15 months later during the following summer, after which up to three annual harvests occur. Over the autumn/winter period and after harvest, plants maintain a rosette growth form that can produce a dense canopy conducive for certain

Corresponding author: S. J. Pethybridge; E-mail: sjp277@ cornell.edu

Mention of a trademark, proprietary product, or vendor does not constitute a guarantee or warranty of the product by the USDA and does not imply its approval to the exclusion of the products or vendors that may also be suitable.

*The $\boldsymbol{e}$-Xtra logo stands for "electronic extra" and indicates that 1 supplementary table is included in the online edition.

Accepted for publication 28 February 2015.

http://dx.doi.org/10.1094/PDIS-12-14-1357-RE

(C) 2015 The American Phytopathological Society foliar diseases. In early spring, multiple stems are formed and within 3 months, flowers are produced on the terminus of each lateral branch. During the harvest process, stems are cut just above the crown and placed in windrows for drying before threshing for seed (MacDonald 1995).

The health of pyrethrum plants is deleteriously affected by a complex of foliar diseases (Pethybridge et al. 2008a), including ray blight caused by Stagonosporopsis tanaceti (Pethybridge and Wilson 1998; Vaghefi et al. 2012); tan spot caused by Microsphaeropsis tanaceti (Pethybridge et al. 2008d); anthracnose caused by Colletotrichum tanaceti (Barimani et al. 2013); pink spot caused by Stemphylium botryosum (Pethybridge et al. 2004); Boeremia blight caused by Boeremia exigua (Jones et al. 2011); and winter blight caused by Alternaria tenuissima (Pethybridge et al. 2004). Foliar disease can deleteriously affect plant size, vigor, and yield potential by reducing green leaf area and photosynthetic ability (Gaunt 1980; Pethybridge et al. 2008b, 2008c; Waggoner and Berger 1987). Traditionally, the most important foliar disease of pyrethrum in Australia has been ray blight, caused by S. tanaceti (Pethybridge and Wilson 1998; Vaghefi et al. 2012). The symptoms of ray blight are well characterized, and the disease is present in most pyrethrum fields (Pethybridge et al. 2003, 2008a). Prior to the implementation of a prophylactic fungicide-based management strategy in 2001, this disease caused substantial yield loss (Pethybridge et al. 2005b, 2008c, 2013). There has been a range of fungicides registered for use on pyrethrum for disease management in spring, including boscalid, cyprodinil, and azoxystrobin. Fungicides are applied in spring to coincide with stem elongation, primarily targeting ray blight 
(Jones et al. 2007; Pethybridge et al. 2008c). These fungicides are utilized in a standard fungicide program that is applied to nearly all pyrethrum produced in Australia (Pethybridge et al. 2008a, 2011, 2013).

In an earlier study conducted during 2000, Alternaria spp., S. tanaceti, and $S$. botryosum were commonly isolated from lesions collected from May to August (austral autumn and winter) with isolation frequencies of 58.9 to $90.9 \%, 11.9$ to $37.8 \%$, and 0 to $9.6 \%$, respectively (Pethybridge et al. 2003). Although defoliation over the autumn and winter period caused by fungal diseases occurs annually, the severity of defoliation has been low and crop damage considered inconsequential. However, since 2009, plants in entire fields have been almost completely defoliated over autumn and winter, which has coincided with failures of the fungicide program traditionally initiated in spring (Pethybridge et al. 2005b). Affected plants generally regrow in spring, but emergence of stems is substantially delayed (Pethybridge et al. 2013). The impact of this defoliation from fungal diseases is important as crop growth and yield are mediated by the duration of healthy canopy area and radiation interception (Gaunt 1980; Waggoner and Berger 1987).

The primary objective of this study was to characterize the prevalence and isolation frequency of fungi associated with foliar disease in Australian pyrethrum fields. A secondary objective was to identify factors that may be influencing suboptimal efficacy from the prophylactic fungicide program applied in spring, including etiology of the foliar disease complex, fungicide sensitivities of dominant pathogens, and selection and timing of fungicide applications for the maintenance of green leaf area to improve yield.

\section{Materials and Methods}

Prevalence and isolation frequency of fungi associated with foliar disease in 2012 and 2013. Isolations. Diseased pyrethrum leaves were collected from commercial pyrethrum fields during 2012 and 2013 to characterize the mycoflora associated with plants affected by foliar disease. Fields were representative of the growing region within Tasmania, Australia, ranging from the towns of Forest $\left(40.51^{\circ} \mathrm{S}, 145.14^{\circ} \mathrm{E}\right)$ to Wesley Vale $\left(41.19^{\circ} \mathrm{S}, 146.46^{\circ} \mathrm{E}\right)$. In 2012 , samples were collected from 26, 27, and 30 commercial fields in the periods April to July (austral winter), August to September (austral spring), and November (austral summer), respectively. In 2013, leaf samples were collected from 72 and 64 commercial fields in June to July (winter) and September to October (spring), respectively. In each field, one diseased leaf was collected from each of 20 to 80 plants selected arbitrarily along a diagonal transect within a non-fungicide treated plot $(10 \times 18 \mathrm{~m})$. In 2012, an intensive sampling was also conducted in two fields (termed "Table Cape" and "Burnie") during July and November. In July, 532 and 380 isolations were conducted from individual leaves collected from the nontreated areas in the Table Cape and Burnie fields, respectively. At the latter sampling time, 288 isolations were made from individual leaves collected along a diagonal transect within each field.

Leaves were stored at $4{ }^{\circ} \mathrm{C}$ for no longer than 4 days before isolations were conducted. Tissue was surface sterilized in $10 \%$ bleach $(0.4 \%$ $\mathrm{NaClO}$ ), rinsed three times in sterile distilled water, and blotted dry. Leaf tissue from the edge of lesions was excised and transferred to petri plates containing $2 \%$ water agar (WA) and incubated in the dark at $20^{\circ} \mathrm{C}$. After 5 days, emerging mycelia were transferred to potato dextrose agar (PDA) (Amyl Media, Dandenong South, Victoria, Australia). Fungi were identified to genus and species based on morphological characters and confirmed by comparison with the respective type cultures for $A$. alternata (New South Wales herbarium reference number DAR 75572), A. tenuissima (DAR 75573), C. tanaceti (Queensland Department of Agriculture, Fisheries and Forestry Plant Pathology herbarium reference number BRIP 57314), M. tanaceti (BRIP 50785), P. chrysanthemicola (Garibaldi and Gullino 1981), I. perplexans (Ingold 1983), and S. tanaceti (BRIP 57320). Agar plugs (5-mm-diameter) of isolates were air dried under sterile conditions and preserved at $-80^{\circ} \mathrm{C}$.

Fungal incidence was summarized as prevalence (percentage of fields where a species was detected) and as isolation frequency (percentage of diseased leaves from which a species was isolated). Observations of disease symptoms were recorded and categorized.
The seven symptom types observed were brown/black lesions initiated from the leaf tip (total number of samples, $n=637$ ); necrotic margins ( $n=171)$; necrotic spots less than $2 \mathrm{~mm}$ in diameter $(n=639)$; necrotic irregular patches not limited by leaf veins $(n=296)$; necrotic lesions limited by a leaf vein and initiated from the petiole $(n=128)$; leaf surfaces almost entirely necrotic $(n=239)$; and necrotic buds $(n=32)$.

Weather data. Rainfall and monthly mean maximum and minimum temperature were obtained from a weather station located at Devonport, Tasmania $\left(41.17^{\circ} \mathrm{S}, 146.43^{\circ} \mathrm{E}\right)$, representative of the coastal production region. The monthly mean maximum and minimum temperatures were calculated as the average of available daily maximum and minimum for the month. The daily maximum and minimum air temperatures were nominally recorded using 9 A.M. local time as a reference point for the previous $24 \mathrm{~h}$.

Data analysis. For each species, a contingency table was constructed to examine the association between time of sampling and presence/absence of an organism based on the total number of isolations at each time of sampling. $\chi^{2}$ analysis was undertaken to test for independence of isolation frequency of a fungal species from time of sampling within each year. Pearson residuals obtained from the $\chi^{2}$ analyses were used as indicators of the strength of association. Residual values greater than 1.96 or less than -1.96 were considered indicators of significant association or dissociation, respectively. Data analysis was conducted in R v. 3.1.2 (R Core Team 2014).

In vitro fungicide sensitivity testing. Fungicide sensitivity assays were conducted to determine if temporal changes in the frequency of certain pathogens and recent disease control failures were correlated with insensitivity to commonly applied fungicides. S. tanaceti and M. tanaceti isolates were obtained in early spring 2009 from fields prior to failures of the spring fungicide program. Additional M. tanaceti isolates were collected in spring of 2011 from fields with high disease severity despite the application of the fungicides in spring. These isolates were tested for their sensitivity to the fungicides boscalid and cyprodinil. Boscalid sensitivity testing was conducted with isolates of $S$. tanaceti $(n=53)$ and M. tanaceti $(n=50)$ collected in 2009. Cyprodinil sensitivity testing was conducted with isolates of $S$. tanaceti $(n=52)$ and M. tanaceti $(n=48)$ collected in the same year. For $M$. tanaceti isolates collected in 2011, sensitivity to boscalid $(n=159)$ and cyprodinil $(n=143)$ was tested.

To conduct in vitro fungicide sensitivity assays, PDA was prepared and autoclaved in $400 \mathrm{ml}$ quantities and cooled in a water bath to $55^{\circ} \mathrm{C}$. A stock solution of fungicide was made by suspending the appropriate quantity of commercial formulation fungicide in a small amount of sterile water in a sterile $15-\mathrm{ml}$ polypropylene centrifuge tube. The stock solution was made up to the appropriate volume with ethanol equivalent to $80 \%(\mathrm{v} / \mathrm{v})$ and left at room temperature for approximately $30 \mathrm{~min}$ for sterilization and solubility (Secor and Rivera 2012). A dilution series $\left(10^{-1}, 10^{-2}\right.$, and $\left.10^{-3}\right)$ was then made, from which appropriate aliquots were added to cooled agar to achieve concentrations of 0 (non-amended control), 0.05, 0.5, 5.0, and $50.0 \mu \mathrm{g}$ a.i. $/ \mathrm{ml}$. The concentration of ethanol within the amended media did not exceed $1 \mathrm{ml} / \mathrm{liter}$.

Fungal isolates were removed from long-term storage at $-80^{\circ} \mathrm{C}$, and grown on PDA in petri plates at $20^{\circ} \mathrm{C}$ in the dark for approximately 7 to 10 days. For each isolate, two to three replicate plates of fungicide-amended media, including a non-amended control, were inoculated with a 3-mm-diameter agar plug taken from the colony margin and then incubated at $20^{\circ} \mathrm{C}$ in the dark. The diameter of the colony on each plate was measured after 10 days along two perpendicular axes and averaged for each plate. The mean diameter per fungicide concentration was expressed as a percentage of the diameter of the non-amended control. The concentrations at which fungal growth were reduced to $50 \%$ or more of the nontreated control $\left(\mathrm{EC}_{50}\right)$ were calculated using probit regression in SAS version 9.1 (SAS Institute, Cary, NC) using a modified program of that described by Hsiang et al. (1997). Data were summarized as the frequency of isolates with $\mathrm{EC}_{50}$ values within each concentration range.

Comparative benefits of autumn and spring applied fungicides. Results of 14 individual trials conducted in $2011(n=1)$ and 2012 $(n=13)$ were combined in an individual participant data meta-analysis 
to assess the efficacy of various fungicide programs applied in autumn and winter compared with the industry standard of spring only. Nelson et al. (2015) provides a summary of an individual participant data meta-analysis in a plant pathology context. The design of all trials was a randomized complete block with treatments replicated four times.

In 2011, a field trial was conducted at West Pine, Tasmania, Australia. Plots were $3.2 \mathrm{~m}$ wide $\times 6 \mathrm{~m}$ long with $1 \mathrm{~m}$ nontreated buffers between plots. Autumn/winter fungicide treatments were 375 and $500 \mathrm{~g}$ a.i./ha fluazinam (as Shirlan, Syngenta Australia); 800 and 1,600 g a. i./ha procymidone (as Fortress, Crop Care Australasia); $500 \mathrm{~g}$ a.i./ha iprodione (as Rovral, Bayer CropScience Australia); $487.5 \mathrm{~g}$ a.i./ha fludioxinil + $325 \mathrm{~g}$ a.i./ha cyprodinil (as Switch, Syngenta Australia); and a nontreated control. Fungicides were applied on 26 May, 22 June, and 25 July with a motorized backpack sprayer fitted with a 1.6-m boom delivering a total volume of 300 liters/ha. Equal numbers of plots with each treatment then received either the commercial standard springfungicide program or were left nontreated in spring (Pethybridge et al. $2008 \mathrm{c}$ ). The standard spring fungicide program is an initial application of $375 \mathrm{~g}$ a.i./ha cyprodinil $+250 \mathrm{~g}$ a.i./ha fludioxonil (as Switch, Syngenta Australia), made when stem height is approximately $5 \mathrm{~cm}$ (generally early to mid-August), followed 10 to 14 days later with an application of $500 \mathrm{~g}$ a.i./ha boscalid (as Filan, NuFarm Australia) + chlorothalonil at 1,008 liters a.i./ha (as Bravo Weather Stik, Syngenta Australia); and a final application of $150 \mathrm{~g}$ a.i./ha azoxystrobin + chlorothalonil at 1,008 liters a.i./ha (as Bravo Weather Stik) 10 days later. Green leaf area was assessed using methods described previously for pyrethrum (Pethybridge et al. 2008b). The normalized difference vegetative index within each plot between 15 and 20 August was measured with a GreenSeeker radiometer (NTech Industries, Ukiah, CA). Readings of canopy reflectance were taken every 100 milliseconds over the entire plot area, and averaged to provide a mean for individual plots. The effect of treatment on defoliation severity was measured between 9 and 13 October using established methods (Pethybridge et al. 2005a). In brief, 20 flowering stems were collected systematically along a diagonal transect across each plot. Stem height and height to defoliation (leaves either completely necrotic or abscised) were measured and used to calculate percent defoliation severity.

On 5 December, the number of flowers per square meter was counted by image analysis (Scott et al. 2011). This information was used in combination with the dry weight of individual flowers and pyrethrin content determined by normal-phase high-performance liquid chromatography (McEldowney and Menary 1988) to calculate pyrethrin yield (Pethybridge et al. 2008c).

Thirteen trials were conducted examining the effect of fungicides applied during autumn/winter and spring on canopy growth, defoliation in spring, and yield. Six trials were located near Table Cape and the remainder near Burnie, Tasmania, during 2012. Plots were $4 \mathrm{~m}$ wide $\times 5 \mathrm{~m}$ long and separated by $1 \mathrm{~m}$ nontreated buffers. Three of the trials at each location had treatments of 375 or $500 \mathrm{~g}$ a.i./ha fluazinam (as Shirlan) applied twice in autumn, and half of the plots also received the spring fungicide program. Treatments that were nontreated for the entire season and autumn only were also included. The remainder of the trials at each location had autumn applications of $500 \mathrm{~g}$ a.i./ha fluazinam, $487.5 \mathrm{~g}$ a.i./ha fludioxinil $+325 \mathrm{~g} / \mathrm{kg}$ cyprodinil, and nontreated plots, and again half also received the spring fungicide program as described above (Pethybridge et al. 2008c). Fungicide applications during autumn and winter were applied on 26 May, 22 June, and 25 July with a motorized backpack sprayer fitted with a 1.6-m boom delivering 300 liters/ha.

Green leaf area, defoliation severity, and yield measurements were conducted as described for the 2011 trial. Green leaf area was assessed within each plot between 18 and 22 August. Stems were collected between 17 and 20 October to estimate defoliation severity. Yield measurements were taken between 5 and 8 December.

Data analysis. The effect of treatments on canopy reflectance, defoliation severity, and pyrethrin yield was expressed relative to the mean of the nontreated control plots within each trial. The natural $\log$ of the response ratio (denoted as $R$ ) was calculated for each treatment as $y_{t} / y_{c}$, where $y_{t}$ is disease intensity in a fungicide-treated plot receiving treatment $t$, and $y_{c}$ is the mean response of all nontreated control plots in that trial. The response ratio was used in place of percent change relative to a nontreated because of the improved statistical properties of the response ratio (Hedges et al. 1999).

The general analysis approach was similar to methods used for analysis of multicenter evaluation of treatments (Littell et al. 2006), as described by Nelson et al. (2015). As described above, various treatments and timings of fungicides were evaluated in a given experiment. As a preliminary step, data were first analyzed to determine if the timing of the fungicides during autumn or winter, the product, or product rate influenced green leaf area, defoliation severity, or yield. To conduct these analyses, the natural logarithm of the response ratio for a given variable was modeled to be dependent on the fixed effect of interest (timing, product, or rate). Trial effects, replication within trial, and an interaction term for trial $\times$ the fixed effect factor in a given model were considered random variables. Analyses were carried out in the GLIMMIX procedure in SAS version 9.4 (SAS Institute, Cary, NC) with denominator degrees of freedom determined using a general Kenward-Roger approximation. A normal distribution was specified with the default identity link function. When covariance parameter estimates were found to be 0 , the random effect was removed from the model and the model was refitted. Least square means were compared by specific contrasts and the lsmeans option available in GLIMMIX.

In the preliminary analysis, timing of fungicide during the autumn/winter period, product, and product rate resulted in statistically similar green leaf area, defoliation severity, and yield. Therefore, data were aggregated across these factors into simple categorical variables reflecting fungicide application during (i) autumn/winter only, (ii) spring only, or (iii) both autumn/winter and spring. Analyses were then repeated as described using data from all trials. For defoliation severity, the analysis was based on $(R+1)$ to avoid taking the logarithm of 0 . After analysis, log response ratios were expressed as percent disease control for ease of interpretation through the equation percent disease control $=100 \times(1-(\exp (R)-1))$. Percent increase in yield and canopy reflectance were obtained through the back-transformation: $100 \times$ $(\exp (R))$.

\section{Results}

Prevalence and isolation frequency of fungi associated with foliar disease in 2012 and 2013. 2012. M. tanaceti and S. tanaceti were the most commonly isolated fungi, being detected in at least 96 and $70 \%$ of fields, respectively, for a given sampling period (Fig. 1A). C. tanaceti occurred in 50\% of fields in winter, $67 \%$ of fields in spring, and $23 \%$ of fields in summer. Alternaria spp. progressively declined in prevalence over the sampling periods, from $92 \%$ of fields in winter to $40 \%$ of fields in summer (Fig. 1A). Itersonilia perplexans occurred at low prevalence in winter ( $8 \%$ of fields), and became more prevalent in spring and summer (93 and $43 \%$ of fields, respectively). S. botryosum and its teleomorph Pleospora herbarum (hereafter referred to as $S$. botryosum) were detected most often during winter (23\% of fields) and $\leq 3 \%$ at other times (Fig. 1A). Paraphoma chrysanthemicola was most often recovered during spring (26\% of fields; Fig. 1A).

$M$. tanaceti had the highest mean isolation frequency (Table 1). For $M$. tanaceti, there was a significant $(P<0.001)$ association between presence and time of sampling (Table 1). Isolation frequency was strongly dissociated with the winter time period, but not strongly associated with spring or summer (Table 1). This corresponded with an increase in mean isolation frequency from winter $(40.8 \%)$ to spring $(55.5 \%)$, with a small reduction in isolation frequency in summer (53.3\%; Table 1). In spring and summer, many fields had high isolation frequencies, with $25 \%$ of fields in spring and summer with isolation frequency of 81.9 and $73.2 \%$ or greater, respectively (Fig. 1A).

For $S$. tanaceti, isolation frequency was temporally associated $(P<$ 0.001 ; Table 1), corresponding with low mean isolation frequencies in winter $(11.8 \%)$ and spring $(9.2 \%)$, followed by an increase in summer (36.5\%; Table 1). In summer, $25 \%$ of fields had isolation frequencies of $67.9 \%$ or greater (Fig. 1A). 
There was a progressive decline in mean isolation frequency of both $C$. tanaceti and Alternaria spp. over the three sampling times. $C$. tanaceti isolation frequency was associated with winter and dissociated with summer $(P<0.001)$, declining from 6.2 to $1.1 \%$ (Table 1). Similarly, mean isolation frequency of Alternaria spp. was significantly $(P<0.001)$ associated with winter sampling
(26.7\%), and dissociated with spring $(4 \%)$ and summer $(1.3 \%$; Table 1). Alternaria spp. were recovered in winter at moderate to high isolation frequencies in many fields, with $25 \%$ of fields having mean isolation frequencies greater than $37 \%$ (Fig. 1A). Mean isolation frequencies of $S$. botryosum, I. perplexans, and $P$. chrysanthemicola were all very low $(\leq 7.7 \%)$ in 2012 (Table 1).

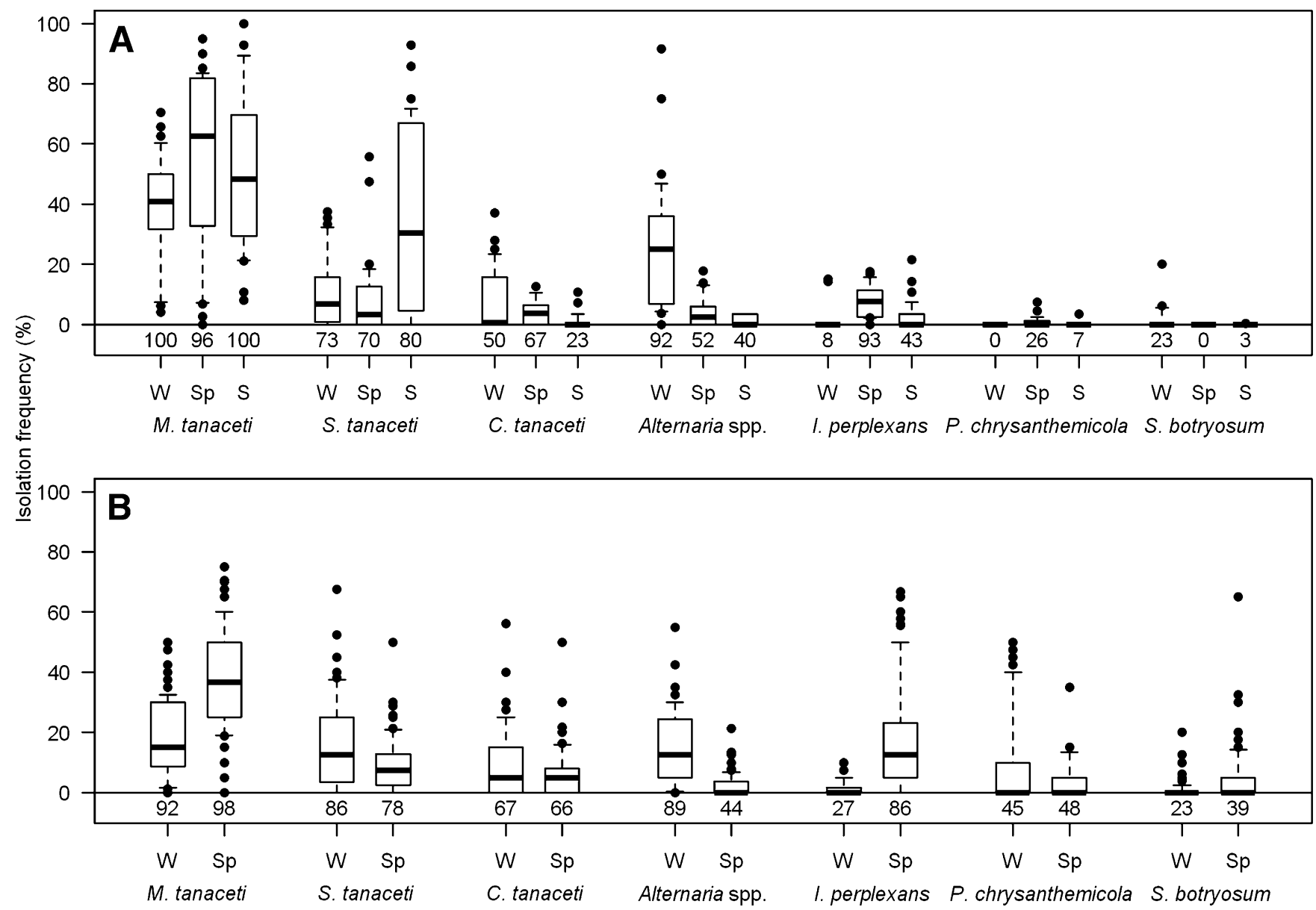

Fig. 1. Frequency of isolation of fungi from pyrethrum leaves with symptoms of winter dieback during winter (W), spring (Sp), and early summer (S) in 2012 (A) and 2013 (B). Leaf samples were collected from 26 to 30 fields in 2012, and 64 to 72 in 2013, depending on sampling period. The boundary of the box indicates the 25th and 75 th percentile, the line within the box indicates the median, whiskers (error bars) indicate the 10th and 90th percentiles, and dots indicate outliers. Numeric values below boxplots are the percentage of fields (prevalence) where an organism was detected. Abbreviations are M. tanaceti $=$ Microsphaeropsis tanaceti; $S$. tanaceti = Stagonosporopsis tanaceti; $C$. tanaceti $=$ Colletotrichum tanaceti; I. perplexans = Itersonilia perplexans; $P$. chrysanthemicola = Paraphoma chrysanthemicola; and S. botryosum = Stemphylium botryosum .

Table 1. $\chi^{2}$ test of association between isolation frequencies of fungi from diseased pyrethrum leaves collected at different times in 2012 and 2013 in Tasmania, Australia

\begin{tabular}{|c|c|c|c|c|c|c|c|}
\hline \multirow[b]{2}{*}{$\begin{array}{l}\text { Sampling } \\
\text { period }\end{array}$} & \multicolumn{7}{|c|}{ Isolation frequency $(\%)^{\mathbf{a}}$} \\
\hline & $\begin{array}{c}\text { Microsphaeropsis } \\
\text { tanaceti }\end{array}$ & $\begin{array}{c}\text { Stagonosporopsis } \\
\text { tanaceti }\end{array}$ & $\begin{array}{c}\text { Colletotrichum } \\
\text { tanaceti }\end{array}$ & $\begin{array}{l}\text { Alternaria } \\
\text { spp. }\end{array}$ & $\begin{array}{l}\text { Stemphylium } \\
\text { botryosum }\end{array}$ & $\begin{array}{l}\text { Itersonilia } \\
\text { perplexans }\end{array}$ & $\begin{array}{c}\text { Paraphoma } \\
\text { chrysanthemicola }\end{array}$ \\
\hline \multicolumn{8}{|l|}{2012} \\
\hline Winter & $40.8(-3.4)$ & $11.9(-3.6)$ & $6.2(3.2)$ & $26.7(16.4)$ & 1.8 & 0.0 & 0.0 \\
\hline Spring & $55.5(1.7)$ & $9.3(-7.0)$ & $4.2(0.9)$ & $4.0(-5.7)$ & 0.0 & 7.7 & 0.9 \\
\hline Summer & $53.3(0.9)$ & $36.5(11.1)$ & $1.1(-3.8)$ & $1.3(-7.4)$ & 0.0 & 3.2 & 0.3 \\
\hline$\chi^{2}(P \text { value })^{\mathrm{b}}$ & $30.6(<0.001)$ & $229.1(<0.001)$ & $26.2(<0.001)$ & $394.6(<0.001)$ & $\mathrm{na}^{\mathrm{c}}$ & na & na \\
\hline \multicolumn{8}{|l|}{2013} \\
\hline Winter & $18.0(-10.7)$ & $16.1(5.0)$ & $9.8(3.9)$ & $15.3(11.8)$ & $1.2(-5.0)$ & $1.1(-13.3)$ & $9.6(6.3)$ \\
\hline Spring & $38.3(10.2)$ & $9.3(-4.8)$ & $7.1(-3.7)$ & $2.4(-11.3)$ & $5.0(4.7)$ & $18.6(12.7)$ & $3.9(-6.0)$ \\
\hline$\chi^{2}(P$ value $)$ & $308.8(<0.001)$ & $54.5(<0.001)$ & $31.4(<0.001)$ & $295.0(<0.001)$ & $47.8(<0.001)$ & $370.7(<0.001)$ & $79.3(<0.001)$ \\
\hline
\end{tabular}

a Isolations in 2012 conducted from 26, 27, and 30 fields in April to July (winter), August and September (spring), and November (summer), from 567, 1,038, and

784 leaves, respectively. In 2013, isolations were conducted from samples collected in 72 and 64 fields between June and July (winter), and September and October (spring), from 2,441 and 2,655 leaves, respectively. Values in parentheses indicate residuals from $\chi^{2}$ analysis associated with presence of a given species for each time period as an indicator of relative association or dissociation.

${ }^{b} \chi^{2}$ test of association and probability presented parenthetically.

${ }^{\mathrm{c}}$ na $=$ not analyzed due to one or more expected cell frequencies $<5$. 
However, while overall mean isolation frequency of I. perplexans was low, in winter $25 \%$ of fields had isolation frequencies of $11.4 \%$ or greater (Fig. 1A).

In the two intensively sampled fields, the mean isolation frequency of M. tanaceti at Table Cape was 9.6 and $8 \%$ in July and November, respectively, with no significant association between isolation frequency and time of sampling (Table 2). However, at Burnie, the isolation frequency of $M$. tanaceti increased from July $(8.4 \%)$ to November $(21.2 \%)$ as indicated by a significant $(P<0.001)$ association with sampling period (Table 2). For S. tanaceti, there was significant $(P<0.001)$ association between isolation frequency and time of sampling at both fields. This corresponded to an increase in isolation frequency between July and November from 7.3 to $22.9 \%$ at Burnie, and from 0 to $6.9 \%$ at Table Cape (Table 2). For I. perplexans, Alternaria spp., and C. tanaceti, there was a significant $(P<0.001)$ association between isolation frequency and time of sampling corresponding to a decrease in isolation frequency between July and November at both fields (Table 2). At Table Cape, these fungi occurred at an isolation frequency of 15 to $28 \%$ in July and less than $0.7 \%$ in November. Similarly, at Burnie they occurred between 14.2 and $21.1 \%$ in July and less than $1.4 \%$ in November (Table 2).

2013. As in 2012, M. tanaceti was the most prevalent pathogen and was detected in at least $92 \%$ of fields in winter and spring (Fig. 1B). S. tanaceti and C. tanaceti were detected in winter in 86 and $67 \%$ of fields, respectively, and in summer in 78 and $66 \%$ of fields, respectively (Fig. 1B). Alternaria spp. were detected in $89 \%$ of fields in winter and $44 \%$ in spring. $P$. chrysanthemicola was detected in $45 \%$ of fields in winter and $48 \%$ of fields in spring. S. botryosum and I. perplexans were detected in 23 and $27 \%$ of fields, respectively, in winter, and 39 and $86 \%$ of fields, respectively, in spring (Fig. 1B).

For $M$. tanaceti, there was a significant $(P<0.001)$ association between mean isolation frequency and time of sampling (Table 1), corresponding to an increase in isolation frequency of $M$. tanaceti from $18 \%$ in winter to $38.3 \%$ in spring (Table 1). Similarly, mean isolation frequency of $S$. tanaceti in fields was significantly associated with winter $(16.1 \%)$ relative to spring $(9.3 \%)$ sampling $(P<$ 0.001; Table 1). Additionally, C. tanaceti, Alternaria spp., and $P$. chrysanthemicola had significant associations with winter relative to spring $(P<0.001$; Table 1$)$. Alternaria spp. were isolated at moderate frequencies during winter with $25 \%$ of fields with isolation frequencies greater than 24\% (Fig. 1B). Conversely, both I. perplexans and $S$. botryosum were associated with spring sampling relative to winter $(P<0.001)$. I. perplexans was observed at moderate isolation frequencies in many fields during spring with $25 \%$ of fields having isolation frequencies between 23.1 and $66.7 \%$ (Fig. 1B).

Association of fungal species with symptoms. Two or more fungi were often isolated from a single tissue piece. M. tanaceti was isolated most consistently from all symptoms (Table 3). S. tanaceti was isolated at highest frequency from necrotic flower buds $(31.3 \%)$ and from brown or black necrotic areas that were initiated from petioles and/or vein-limited (25\%). C. tanaceti was isolated most frequently from leaf necrotic spots (20.7\%). I. perplexans was isolated most frequently from leaves which were almost entirely necrotic $(40.6 \%)$ or brown/black necrotic patches initiated at the leaf tips $(24.5 \%)$. S. botryosum and $P$. chrysanthemicola were recovered at low frequency from all symptoms (Table 3 ).

Weather data. The long-term average cumulative rainfall between March and August (autumn and winter) for the years 1993 to 2013 was $374.9 \mathrm{~mm}$ (Supplementary Table S1). For the periods 2005 to 2008 and 2009 to 2012, total rainfall between March and August ranged between 11 and $159.4 \mathrm{~mm}$ below, and 11 and $79 \mathrm{~mm}$ above the long-term average, respectively. Mean monthly maximum and minimum temperatures did not differ markedly over the period between March and August between 2005 and 2008, and 2009 to 2012, and in comparison with the long-term average.

In vitro fungicide sensitivity testing. All $S$. tanaceti isolates collected in 2009 were sensitive to boscalid with an $\mathrm{EC}_{50}<0.5$ $\mu \mathrm{g}$ a.i./ml (Table 4). In contrast, isolates of $M$. tanaceti collected in 2009 exhibited a range of sensitivities to boscalid. Some isolates were relatively insensitive with $14 \%$ having an $\mathrm{EC}_{50}>50$ $\mu \mathrm{g}$ a.i./ml (Table 4). In 2011, 60.4\% of $M$. tanaceti isolates collected from fields with severe winter dieback had an $\mathrm{EC}_{50}>50 \mu \mathrm{g}$ a.i. $/ \mathrm{ml}$. In 8 of the 12 fields with severe winter dieback, over half of the isolates tested had an $\mathrm{EC}_{50}>50 \mu \mathrm{g}$ a.i./ml.

Isolates of $S$. tanaceti collected in 2009 were highly sensitive to cyprodinil with $96 \%$ of isolates with an $\mathrm{EC}_{50}<5.0 \mu \mathrm{g}$ a.i. $/ \mathrm{ml}$, and all isolates had an $\mathrm{EC}_{50}<50.0 \mu \mathrm{g}$ a.i./ml (Table 4). M. tanaceti isolates collected in 2009 were also sensitive to cyprodinil with $98 \%$ of isolates with similar $\mathrm{EC}_{50}$ profiles as $S$. tanaceti. Similarly, $M$. tanaceti isolates collected from fields with severe winter dieback in 2011 were sensitive to cyprodinil with $94 \%$ of isolates with an $\mathrm{EC}_{50}<5.0 \mu \mathrm{g}$ a.i./ml and all with an $\mathrm{EC}_{50}<50.0 \mu \mathrm{g}$ a.i. $/ \mathrm{ml}$ (Table 4).

Comparative benefits of autumn and spring applied fungicides. Application of fungicides during autumn improved green leaf area in August $(P<0.001$; Fig. $2 \mathrm{~A})$. Plots that were treated only in spring and suffered extensive defoliation had green leaf area similar to that of nontreated plots. There was evidence that the timing of fungicides applied in autumn influenced green leaf area in September $(P=0.056)$. However, the improvement in green leaf in September due to fungicide treatment during autumn was more muted in comparison with August. In September, green leaf area was similar in plots treated both in autumn and spring, or spring only (Fig. 2B). Disease control in September was significantly improved when plots were treated with fungicides during autumn, independent of whether a spring fungicide program was applied $(P<$ 0.0001; Fig. 2C). However, improvements in disease control from

Table 2. $\chi^{2}$ test of association between isolation frequencies of fungi from diseased pyrethrum leaves collected at different times across intensively sampled fields in 2012 in Tasmania, Australia

\begin{tabular}{|c|c|c|c|c|c|c|c|}
\hline \multirow[b]{2}{*}{ Month } & \multirow[b]{2}{*}{ Field } & \multirow[b]{2}{*}{$n^{\mathbf{b}}$} & \multicolumn{5}{|c|}{ Isolation frequency $(\%)^{\mathrm{a}}$} \\
\hline & & & $\begin{array}{c}\text { Microsphaeropsis } \\
\text { tanaceti }\end{array}$ & $\begin{array}{c}\text { Stagonosporopsis } \\
\text { tanaceti }\end{array}$ & $\begin{array}{l}\text { Itersonilia } \\
\text { perplexans }\end{array}$ & $\begin{array}{l}\text { Alternaria } \\
\text { spp. }\end{array}$ & $\begin{array}{c}\text { Colletotrichum } \\
\text { tanaceti }\end{array}$ \\
\hline July & Table Cape & 532 & $9.6(0.4)$ & $7.3(-3.5)$ & $15.0(3.7)$ & $17.5(4.1)$ & $28.0(5.3)$ \\
\hline November & & 288 & $7.9(-0.6)$ & $22.9(4.8)$ & $0.7(-5.0)$ & $0.4(-5.6)$ & $0.0(-7.2)$ \\
\hline$\chi^{2}(P \text { value })^{\mathrm{c}}$ & & & $0.4(0.525)$ & $39.3(<0.001)$ & $41.1(<0.001)$ & $52.4(<0.001)$ & $96.7(<0.001)$ \\
\hline July & Burnie & 380 & $8.4(-2.9)$ & $0.0(-3.4)$ & $14.2(3.6)$ & $16.1(4.0)$ & $21.1(5.0)$ \\
\hline November & & 288 & $21.2(3.3)$ & $6.9(3.9)$ & $1.4(-4.2)$ & $1.4(-4.5)$ & $0.4(-5.7)$ \\
\hline$\chi^{2}(P$ value $)$ & & & $21.2(<0.001)$ & $24.9(<0.001)$ & $32.4(<0.001)$ & $38.5(<0.001)$ & $64.0(<0.001)$ \\
\hline
\end{tabular}

a Percentage of host tissue samples from which a given species was isolated. Values in parentheses indicate residuals from $\chi^{2}$ analysis associated with presence of a given species for each time period as an indicator of relative association or dissociation.

${ }^{b}$ Number of isolations conducted at each sampling period.

${ }^{\mathrm{c}} \chi^{2}$ test of association and probability presented parenthetically. 
fungicide applications made in August did not persist into October (Fig. 2D). Disease control in October required application of fungicides in spring, independent of fungicide applications made during autumn $(P=0.003$; Fig. 2D). Similarly, in this analysis, application of fungicides in spring were associated with the greatest improvement in pyrethrin yield ( $P=0.008$; Fig. $2 \mathrm{E})$.

\section{Discussion}

Temporal changes in the prevalence and isolation frequency of fungi may be associated with differences in the responses of individual fungal species to environmental conditions, such as temperature and rainfall, seasonal changes in host susceptibility, and/or interspecies competition. A key finding in this study is that $M$. tanaceti has emerged as the dominant species associated with foliar disease of pyrethrum during winter and spring. This represents a substantial shift from previous studies where $M$. tanacet $i$ was widespread in pyrethrum fields but present at only low frequencies and not associated with severe defoliation or economic damage (Pethybridge et al. 2003). In addition, previous studies showed $S$. tanaceti to be the dominant pathogen of pyrethrum in spring. In a survey of 25 pyrethrum fields in 2000 , $S$. tanaceti occurred at an average isolation frequency from leaves of $\leq 19.4 \%$ in early to midwinter, $37.8 \%$ in late winter, and 56.9 to $82.7 \%$ over spring (Pethybridge et al. 2003). The current study also found a low isolation frequency of $S$. tanaceti in winter but differed from previous studies in that no increase was detected in spring. Furthermore, the increase in $M$. tanaceti during winter and spring was associated with a shift in the increase in isolation frequency of $S$. tanaceti, from spring to summer. These results suggest the inoculum density of $M$. tanaceti may increase more over winter than $S$. tanaceti and out-compete $S$. tanaceti, leading to $M$. tanaceti being the most prevalent species associated with disease of emerging stems and foliage in spring. There are several potential reasons for this shift, including higher rainfall in winter months in northern Tasmania in recent years, which may have favored $M$. tanaceti. Other factors might include the presence of currently unknown alternative hosts near pyrethrum fields and a teleomorph of M. tanaceti.

A complex of other fungi pathogenic to pyrethrum was detected in these studies, but these organisms appear to be (at present) a minor component of the foliar microflora. C. tanaceti, the cause of anthracnose of pyrethrum (Barimani et al. 2013), was commonly associated with small necrotic spots. This fungus occurred at highest frequency in autumn through winter and spring in 2012 and 2013, but during the summer of 2012 was less frequent. C. tanaceti was not detected in earlier surveys (Pethybridge et al. 2003). $S$. botryosum, the cause of pink spot of pyrethrum (Pethybridge et al. 2004), occurred at low prevalence and incidence in 2012 but was more prevalent in 2013 with both the anamorph and teleomorph (Pleospora herbarum) observed directly on diseased tissue. Although the mean isolation frequency of $S$. botryosum was generally low $(<5 \%)$ across sampling periods, isolation frequency among fields was highly variable (up to a maximum of 65\%). In 2000 and 2001 , the mean incidence of $S$. botryosum on leaves isolated in similar crop phenological stages was 4.7 and $22.6 \%$, respectively (Pethybridge et al. 2003). Alternaria spp. (predominantly A. tenuissima; Pethybridge et al. 2003) were isolated most often during autumn and winter and by summer had become a minor component of the mycoflora, which is similar to an earlier study (Pethybridge et al. 2003). I. perplexans occurred at low mean isolation frequency in autumn/winter but increased in spring during 2012 and 2013, and in some fields in 2013 , isolation frequency was moderate to high. $P$. chrysanthemicola occurred at a low prevalence and incidence in 2012 but had the highest isolation frequency in winter 2012 and in spring of 2013. P. chrysanthemicola and I. perplexans

Table 3. Isolation frequency (\%) of fungi from disease symptoms on pyrethrum foliage and buds collected from fields in 2012 and 2013 in Tasmania, Australia

\begin{tabular}{|c|c|c|c|c|c|c|c|}
\hline \multirow[b]{2}{*}{ Symptom } & \multirow[b]{2}{*}{$n^{\mathbf{b}}$} & \multicolumn{6}{|c|}{ Isolation frequency $(\%)^{\mathbf{a}}$} \\
\hline & & $\begin{array}{l}\text { Microsphaeropsis } \\
\text { tanaceti }\end{array}$ & $\begin{array}{l}\text { Stagonosporopsis } \\
\text { tanaceti }\end{array}$ & $\begin{array}{l}\text { Colletotrichum } \\
\text { tanaceti }\end{array}$ & $\begin{array}{l}\text { Stemphylium } \\
\text { botryosum }\end{array}$ & $\begin{array}{l}\text { Itersonilia } \\
\text { perplexans }\end{array}$ & $\begin{array}{c}\text { Paraphoma } \\
\text { chrysanthemicola }\end{array}$ \\
\hline $\begin{array}{l}\text { Necrotic lesions initiated from } \\
\text { leaf tips }\end{array}$ & 637 & 49.8 & 13.3 & 2.5 & 6.1 & 24.5 & 3.8 \\
\hline Necrotic margins & 171 & 29.1 & 7.8 & 1.5 & 3.6 & 14.3 & 2.2 \\
\hline $\begin{array}{l}\text { Necrotic spots }(\leq 2 \mathrm{~mm} \\
\text { diameter) }\end{array}$ & 639 & 49.1 & 11.9 & 20.7 & 4.2 & 9.2 & 4.9 \\
\hline Necrotic patches crossing veins & 296 & 55.1 & 15.5 & 2.7 & 4.7 & 18.2 & 3.7 \\
\hline $\begin{array}{l}\text { Necrotic lesion initiated from } \\
\text { petiole and vein-limited }\end{array}$ & 128 & 50.8 & 25.0 & 7.8 & 4.7 & 7.8 & 3.9 \\
\hline Leaf entirely necrotic & 239 & 47.7 & 6.7 & 0.4 & 3.4 & 40.6 & 1.3 \\
\hline Necrotic flower buds & 32 & 65.6 & 31.3 & 0 & 0 & 3.1 & 0 \\
\hline
\end{tabular}

a Frequency of isolation of each fungus/total number of isolations conducted for each symptom $\times 100$.

b Number of isolations.

Table 4. Distribution of growth reduction responses to the fungicides boscalid and cyprodinil by Stagonosporopsis tanaceti and Microsphaeropsis tanaceti isolates collected from diseased pyrethrum leaves in 2009 and 2011

\begin{tabular}{|c|c|c|c|c|c|c|}
\hline \multirow[b]{3}{*}{$\mathrm{EC}_{50}$ concentration range } & \multicolumn{3}{|c|}{ Boscalid } & \multicolumn{3}{|c|}{ Cyprodinil } \\
\hline & \multirow{2}{*}{$\begin{array}{c}\begin{array}{c}\text { Stagonosporopsis } \\
\text { tanaceti }\end{array} \\
2009\end{array}$} & \multicolumn{2}{|c|}{$\begin{array}{c}\text { Microsphaeropsis } \\
\text { tanaceti }\end{array}$} & \multirow{2}{*}{$\begin{array}{c}\begin{array}{c}\text { Stagonosporopsis } \\
\text { tanaceti }\end{array} \\
2009\end{array}$} & \multicolumn{2}{|c|}{$\begin{array}{c}\text { Microsphaeropsis } \\
\text { tanaceti }\end{array}$} \\
\hline & & 2009 & 2011 & & 2009 & 2011 \\
\hline 0 to 0.05 & 98 & 18 & 0 & 0 & 0 & 53.1 \\
\hline 0.05 to 0.5 & 2 & 26 & 4.4 & 6 & 81 & $\mathrm{nt}^{\mathrm{a}}$ \\
\hline 0.5 to 5 & 0 & 24 & 3.8 & 90 & 17 & 41.3 \\
\hline 5 to 50 & 0 & 18 & 31.4 & 4 & 2 & $5.6^{\mathrm{b}}$ \\
\hline$>50$ & 0 & 14 & 60.4 & 0 & 0 & nt \\
\hline$n^{\mathrm{c}}$ & 53 & 50 & 159 & 52 & 48 & 143 \\
\hline
\end{tabular}

${ }^{a}$ Not tested at this concentration. Microsphaeropsis tanaceti isolates in 2011 were tested only at $0,0.05,0.5$, and $5.0 \mu \mathrm{g}$ cyprodinil $/ \mathrm{ml}$.

b $\mathrm{EC}_{50}>5 \mu \mathrm{g} / \mathrm{ml}$ as isolates were not tested at $50.0 \mu \mathrm{g}$ a.i. $/ \mathrm{ml}$.

c Number of isolates tested. 
were not observed in previous work (Pethybridge et al. 2003). The pathogenicity of I. perplexans and $P$. chrysanthemicola to pyrethrum is unknown, but both are pathogens of related chrysanthemum species (Dosdall 1956; Garibaldi and Gullino 1981; Ingold 1983; McGovern et al. 2006; McRitchie et al. 1973; Srivastava 1953).
Their pathogenicity and relative importance to pyrethrum requires further clarification.

As the surveys were conducted in areas of commercial fields that did not receive fungicides, seasonal changes in the isolation frequency of fungi were largely independent of fungicide application.
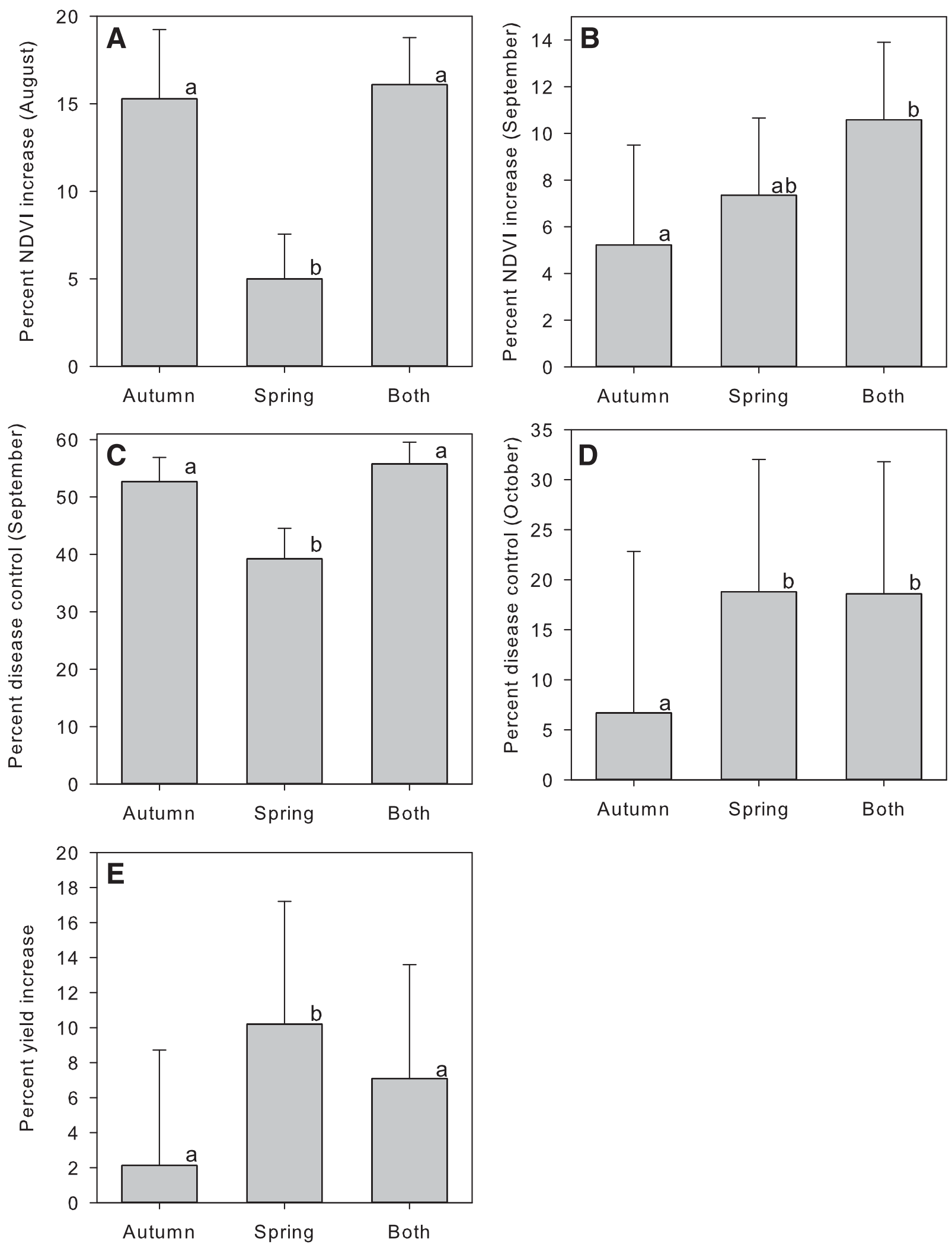

Fig. 2. Association between the increase in green leaf area expressed as normalized difference vegetative index (NDVI) in August (A) and September (B), reduction in defoliation in September $(\mathbf{C})$ and October $(\mathbf{D})$, and flower yield increase $(\mathbf{E})$ due to fungicides applied in autumn, spring, or both. Data are least square means and standard errors from 14 fungicide trials conducted during 2011 and 2012 in Tasmania, Australia. Means with the same letter are not significantly different $(\alpha=0.05)$ according to a mixed model analysis conducted over all data from the 14 trials. See text for a detailed description of the treatments and data analysis. 
However, this study suggests that changes in fungicide sensitivity may have contributed to the emergence of $M$. tanaceti as the dominant pathogen associated with foliar disease. The majority of isolates of $M$. tanaceti obtained from fields that failed to respond to fungicides in spring 2011 were insensitive to $50.0 \mu \mathrm{g}$ a.i. $/ \mathrm{ml}$ of boscalid. In contrast, only $14 \%$ of $M$. tanaceti isolates collected in 2009 were insensitive to the same concentration of boscalid. The change in the distribution and frequency of $M$. tanaceti and disease severity observed appears to be related, at least in part, to reduced sensitivity in the $M$. tanaceti population to boscalid. By comparison, isolates of $S$. tanaceti collected over the same period showed no evidence of reduced sensitivity to boscalid. Thus, application of boscalid in recent years may have given $M$. tanaceti a competitive advantage over $S$. tanaceti and contributed to the former becoming a dominant pathogen. The finding that the majority of $S$. tanaceti and $M$. tanaceti isolates were sensitive to low concentrations of cyprodinil corroborates our field observations in 2011 that fungicides containing cyprodinil effectively suppressed winter dieback.

The molecular basis of boscalid resistance in M. tanaceti is unknown at present, but the phenotype of boscalid insensitivity is reported herein. Boscalid and cyprodinil have been applied annually to all pyrethrum fields since 2005 and 2009, respectively. These fungicides have a medium to high risk for resistance development (Brent and Hollomon 1998; Hewitt 1998; Jutsum et al. 1998) and have been critical in disease management, and thus realizing stable, high yields in pyrethrum (Pethybridge et al. 2013). Resistance to boscalid emerged within 4 years of its first use on pyrethrum despite widespread adoption of best management practices for fungicide resistance embedded in the standard fungicide program used by essentially all of the industry (Gent et al. 2011). The perennial nature of pyrethrum production exposes pathogen populations to repeated selection pressure from the same fungicide, which could have contributed to the development of resistance to boscalid within $M$. tanaceti. This suggests that $M$. tanaceti isolates were either inherently less sensitive to boscalid, able to develop resistance to boscalid due to biology, or resistant isolates were introduced from outside sources. At this time, the lifecycle of $M$. tanaceti is unknown. Studies are underway to elucidate alternate hosts, the presence of its teleomorph, and possible contributions to resistance development.

The emergence of $M$. tanaceti as the dominant foliar pathogen of pyrethrum highlights the urgent need for integrated disease management approaches that reduce reliance on fungicides. Seed has been shown to be a source of primary inoculum for M. tanaceti and other foliar pathogens of pyrethrum (Pethybridge et al. 2006). Reducing the potential for introducing boscalid-insensitive $M$. tanaceti isolates within planting material should be prioritized for disease management. This could include the establishment of seed crops in low-rainfall environments and locations that are isolated from commercial fields.

\section{Acknowledgments}

We gratefully acknowledge the assistance of Mr. Craig Palmer (University of Tasmania), Lynden Head (Botanical Resources Australia Pty. Ltd. [BRA]), and growers for access to fields. We also acknowledge the financial supporters of our programs including BRA, the Pyrethrum Growers' Research and Development Committee, matched funding from the Australian Commonwealth Government through project PY12001 facilitated by Horticulture Australia Ltd., in-kind support of the Tasmanian Institute of Agriculture, and the United States Department of Agriculture - Agricultural Research Service (USDA-ARS) CRIS 5358-21000046-00. Thanks also to Megan Twomey (USDA-ARS) and Cindy Ocamb (Oregon State University, Corvallis, OR) for providing constructive comments on earlier versions of this manuscript.

\section{Literature Cited}

Barimani, M., Pethybridge, S. J., Vaghefi, N., Hay, F. S., and Taylor, P. W. J. 2013. A new anthracnose disease of pyrethrum caused by Colletotrichum tanaceti sp. nov. Plant Pathol. 62:1248-1257.

Brent, K. J., and Hollomon, D. W. 1998. Fungicide Resistance: The Assessment of Risk. Global Crop Protection Federation, Brussels, Belgium.

Casida, J. E. 1980. Pyrethrum flowers and pyrethroid insecticides. Environ. Health Perspect. 34:189-202.

Dosdall, L. T. 1956. Petal blight of chrysanthemums incited by Itersonilia perplexans. Phytopathology 46:231-232.
Garibaldi, A., and Gullino, M. I. 1981. Root rot of chrysanthemum caused by Phoma chrysanthemicola Hollos f. sp. chrysanthemicola Schn. Et Boerema in Italy. Inf. Fitopatol. 31:27-30.

Gaunt, R. E. 1980. Physiological basis of yield loss. Pages 98-111 in: Crop loss assessment, Proc. E. C. Stakman Commemorative Symposium. P. S. Teng and S. V. Krupa, eds. University of Minnesota Agric. Exp. Stn. Miscellaneous Publication 7.

Gent, D. H., De Wolf, E., and Pethybridge, S. J. 2011. Perceptions of risk, risk aversion, and barriers to adoption of decision support systems and integrated pest management: An Introduction. Phytopathology 101:640-643.

Hedges, L. V., Gurevitch, J., and Curtis, P. S. 1999. The meta-analysis of response ratios in experimental ecology. Ecology 80:1150-1156.

Hewitt, H. G. 1998. Fungicides in crop protection. CABI Publishing, Wallingford, UK.

Hsiang, T., Yang, L., and Barton, W. 1997. Baseline sensitivity and cross-resistance to demethylation-inhibiting fungicides in Ontario isolates of Sclerotinia homoeocarpa. Eur. J. Plant Pathol. 103:409-416.

Ingold, C. T. 1983. Structure and development of an isolate of Itersonilia perplexans. Trans. Br. Mycol. Soc. 80:365-368.

Jones, S. J., Hay, F. S., Harrington, T. C., and Pethybridge, S. J. 2011. First report of Boeremia blight caused by Boeremia exigua var. exigua on pyrethrum in Australia. Plant Dis. 95:1478.

Jones, S. J., Pethybridge, S. J., Hay, F. S., Groom, T., and Wilson, C. R. 2007 Baseline sensitivity of Australian Phoma ligulicola isolates from pyrethrum to azoxystrobin and difenoconazole. J. Phytopathol. 155:377-380.

Jutsum, A. R., Heaney, S. P., Perrin, B. M., and Wege, P. J. 1998. Pesticide resistance: assessment of risk and the development and implementation of effective management strategies. Pestic. Sci. 54:435-446.

Littell, R. C., Milliken, G. A., Stroup, W. W., Wolfinger, R. D., and Schabenberger, O. 2006. SAS for Mixed Models. SAS Institute Inc., Cary, NC.

MacDonald, W. L. 1995. Pyrethrum flowers - Production in Australia. Pages 55-66 in: Pyrethrum Flowers: Chemistry, Toxicology and Uses. J. E. Casida and G. B. Quistad, eds. Oxford University Press, New York.

McEldowney, A., and Menary, R. A. 1988. Analysis of pyrethrins in pyrethrin extracts by high-performance liquid chromatography. J. Chromatogr. 447: 239-243.

McGovern, R. J., Horita, H., Stiles, C. M., and Seijo, T. E. 2006. Host range of Itersonilia perplexans and management of Itersonilia petal blight of China aster. Plant Health Prog. Online publication.

McRitchie, J. J., Kimbrough, J. W., and Englehard, A. W. 1973. Itersonilia petal blight of chrysanthemum in Florida. Plant Dis. Rep. 57:181-182.

Nelson, M. E., Gent, D. H., and Grove, G. G. 2015. Meta-analysis reveals a critical period for management of powdery mildew on hop cones. Plant Dis. 99: 632-640.

Pethybridge, S. J., Esker, P. D., Hay, F. S., Wilson, C. R., and Nutter, F. W., Jr. 2005a. Spatiotemporal description of epidemics caused by Phoma ligulicola in Tasmanian pyrethrum fields. Phytopathology 95:648-658.

Pethybridge, S. J., Gent, D. H., Groom, T., and Hay, F. S. 2013. Minimizing crop damage through understanding relationships between pyrethrum phenology and ray blight disease severity. Plant Dis. 97:1431-1437.

Pethybridge, S. J., Gent, D. H., and Hay, F. S. 2011. Epidemics of ray blight on pyrethrum are linked to seed contamination and overwintering inoculum of Phoma ligulicola var. inoxydabilis. Phytopathology 101:1112-1121.

Pethybridge, S. J., Hay, F. S., Esker, P. D., Gent, D. H., Wilson, C. R., and Nutter, F. W., Jr. 2008a. Diseases of pyrethrum in Tasmania: challenges and prospects for management. Plant Dis. 92:1260-1272.

Pethybridge, S. J., Hay, F. S., Esker, P. D., Groom, T., Wilson, C. R., and Nutter, F. W., Jr. 2008b. Visual and radiometric assessments for yield losses caused by ray blight in pyrethrum. Crop Sci. 48:343-352.

Pethybridge, S. J., Hay, F. S., and Groom, T. 2003. Seasonal fluctuations in fungi associated with pyrethrum foliage in Tasmania. Australas. Plant Pathol. 32 223-230.

Pethybridge, S. J., Hay, F. S., Groom, T., and Wilson, C. R. 2008c. Improving fungicide-based management of ray blight disease in Tasmanian pyrethrum fields. Plant Dis. 92:887-895.

Pethybridge, S. J., Hay, F. S., Jones, S. J., Wilson, C. R., and Groom, T. 2006 Seedborne infection of pyrethrum by Phoma ligulicola. Plant Dis. 90: 891-897.

Pethybridge, S. J., Hay, F. S., and Wilson, C. R. 2004. Pathogenicity of fungi commonly isolated from foliar disease in Tasmanian pyrethrum crops. Australas. Plant Pathol. 33:441-444.

Pethybridge, S. J., Hay, F. S., Wilson, C. R., and Groom, T. 2005b. Development of a fungicide-based management strategy for foliar disease caused by Phoma ligulicola in Tasmanian pyrethrum fields. Plant Dis. 89:1114-1120.

Pethybridge, S. J., Jones, S. J., Shivas, R. G., Hay, F. S., Wilson, C. R., and Groom, T. 2008d. Tan spot: a new disease of pyrethrum caused by Microsphaeropsis tanaceti sp. Nov. Plant Pathol. 57:1058-1065.

Pethybridge, S. J., and Wilson, C. R. 1998. Confirmation of ray blight disease of pyrethrum in Australia. Australas. Plant Pathol. 27:45-48.

R Core Team. 2014. R: A language and environment for statistical computing. R Foundation for Statistical Computing, Vienna, Austria. http://www.R-project org/ 
Scott, J. B., Pethybridge, S. J., and Hay, F. S. 2011. Pyrethrum yield estimation by digital image analysis. Phytopathology 101:S162.

Secor, G. A., and Rivera, V. V. 2012. Fungicide resistance assays for fungal plant pathogens. Pages 385-392 in: Plant Fungal Pathogens: Methods and Protocols, Methods in Molecular Biology, vol. 835. M. D. Bolton and B. P. H. J. Thomma, eds. Humana Press, NY.

Srivastava, S. N. S. 1953. On the occurrence of Phoma chrysanthemicola Hollos on Chrysanthemum sp. Curr. Sci. 22:216.
Vaghefi, N., Pethybridge, S. J., Ford, R., Nicolas, M. E., Crous, P. W., and Taylor, P. W. J. 2012. Stagonosporopsis spp. associated with ray blight disease of Asteraceae. Australas. Plant Pathol. 41:675-686.

Waggoner, P. E., and Berger, R. D. 1987. Defoliation, disease, and growth Phytopathology 77:393-398.

Zito, S. W., Zieg, R. G., and Staba, E. J. 1983. Distribution of pyrethrins in oil glands and leaf tissue of Chrysanthemum cinerariaefolium. J. Med. Plant Res. 47:205-207. 